\title{
COMPARISON OF HEATED HUMIDIFIED HIGH FLOW NASAL CANNULA AND NON-INVASIVE VENTILATION ON POST- EXTUBATION OUTCOME IN HIGH RISK CHILDREN - A RANDOMIZED CLINICAL NON-INFERIORITY TRIAL
}

\author{
mukul pandey ${ }^{1}$, Anil Sachdev ${ }^{1}$, Neeraj Gupta ${ }^{1}$, and Dhiren Gupta ${ }^{1}$ \\ ${ }^{1}$ Sir Ganga Ram Hospital
}

July 27, 2020

\begin{abstract}
Objective: It was hypothesized that heated humidified high flow nasal cannula (HFNC) is non-inferior to non- invasive ventilation (NIV) for preventing reintubation in high risk children. Design: Prospective randomized clinical non-inferiority trial Setting: Single centre study in a 12-bed multidisciplinary paediatric intensive care unit (PICU) in Delhi. Patients: All children (1month -18years) receiving invasive mechanical ventilation longer than 48 hours and ready for scheduled extubation. Intervention: Heated humidified high flow nasal cannula(HFNC) or Non-invasive ventilation (NIV) Measurements and Main Results: Of total 230 patients enrolled, 139 were analysed (3 left against medical advice), out of which 70 (50.4\%) received NIV and 69 (49.6\%) HFNC. Mean duration of intubation was $150.8 \pm 74.3$ hours in NIV group vs $138.5 \pm 81.9$ hours in HFNC group ( $\mathrm{p}=0.16)$. Out of 139 children, $15(10.8 \%)$ were re-intubated; $6(8.6 \%)$ in the NIV group vs 9 (13\%) in the HFNC group (absolute difference $4.4 \% ; \mathrm{p}=0.42$ ). Median time to re-intubation did not differ between the group; NIV group 4 hours (IQR 1.7-12.5hours) vs HFNC group 3.7 hours (IQR 2-4hours) (absolute difference, 0.3 hours; $\mathrm{p}=0.50$ ). Mean post extubation PICU length of stay was significantly lower in HFNC group ( $3.5 \pm 2.5$ days) vs NIV group $(4.1 \pm 2.3$ days; $\mathrm{p}=0.01)$. There were multiple reasons for failure of assigned intervention which were comparable in both groups. These included : stridor, impaired consciousness (fall in GCS $>2$ ), haemodynamic instability, inability to clear airway, increased work of breathing, hypoxemia, respiratory acidosis. There was no mortality in either group within 48 hours of extubation. Conclusion: Among high-risk children who had undergone extubation, HFNC therapy was found to be non-inferior to NIV with respect to the re-intubation rate.
\end{abstract}

\section{Hosted file}

Mukul Panday manuscriptR6_15-7-20.doc available at https://authorea.com/users/346310/ articles/472416-comparison-of-heated-humidified-high-flow-nasal-cannula-and-noninvasive-ventilation-on-post-extubation-outcome-in-high-risk-children-a-randomizedclinical-non-inferiority-trial

\section{Hosted file}

results_table_final.docx available at https://authorea.com/users/346310/articles/472416comparison-of-heated-humidified-high-flow-nasal-cannula-and-non-invasive-ventilationon-post-extubation-outcome-in-high-risk-children-a-randomized-clinical-non-inferioritytrial 